
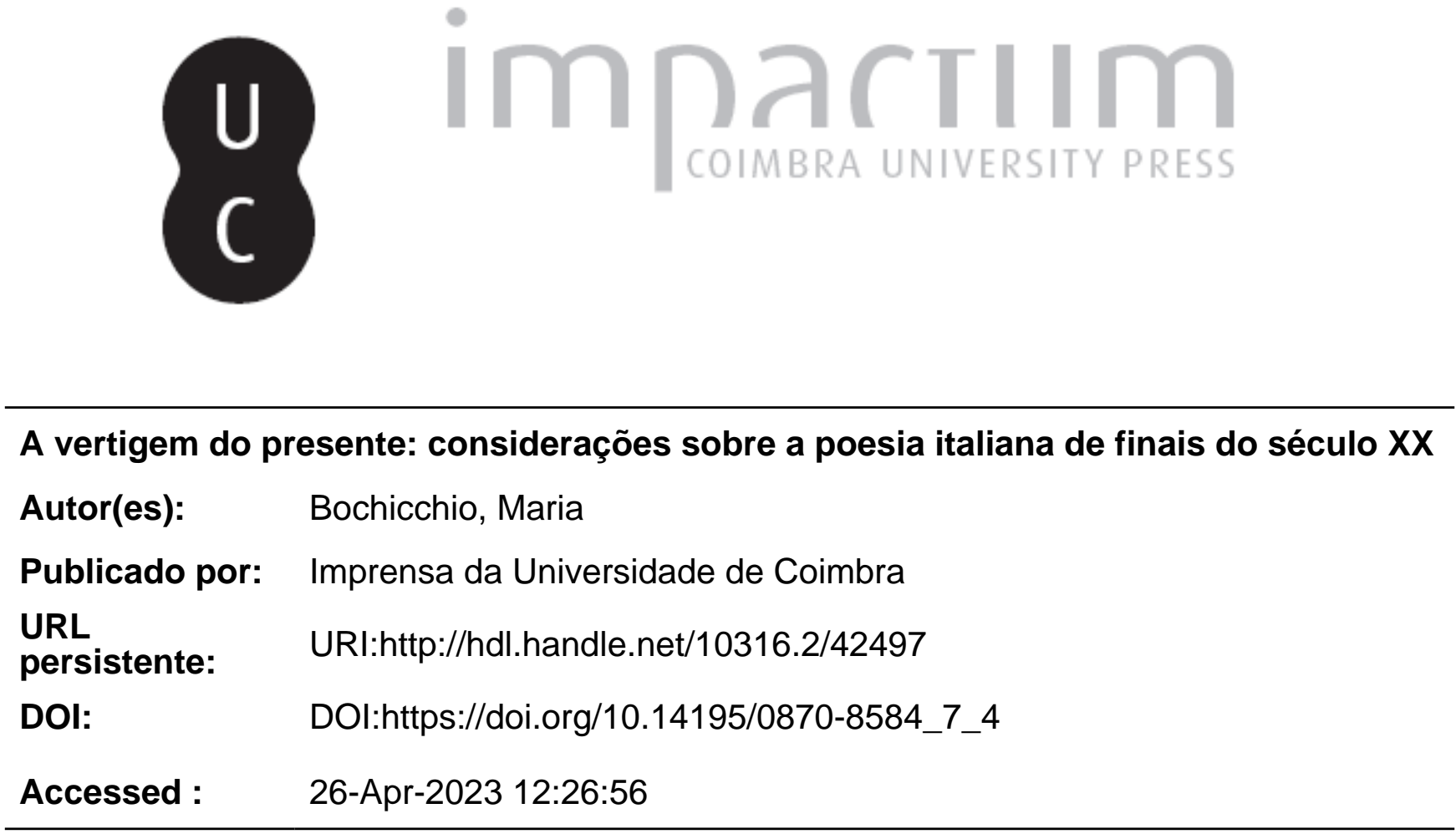

A navegação consulta e descarregamento dos títulos inseridos nas Bibliotecas Digitais UC Digitalis, UC Pombalina e UC Impactum, pressupõem a aceitação plena e sem reservas dos Termos e Condições de Uso destas Bibliotecas Digitais, disponíveis em https://digitalis.uc.pt/pt-pt/termos.

Conforme exposto nos referidos Termos e Condições de Uso, o descarregamento de títulos de acesso restrito requer uma licença válida de autorização devendo o utilizador aceder ao(s) documento(s) a partir de um endereço de IP da instituição detentora da supramencionada licença.

Ao utilizador é apenas permitido o descarregamento para uso pessoal, pelo que o emprego do(s) título(s) descarregado(s) para outro fim, designadamente comercial, carece de autorização do respetivo autor ou editor da obra.

Na medida em que todas as obras da UC Digitalis se encontram protegidas pelo Código do Direito de Autor e Direitos Conexos e demais legislação aplicável, toda a cópia, parcial ou total, deste documento, nos casos em que é legalmente admitida, deverá conter ou fazer-se acompanhar por este aviso. 


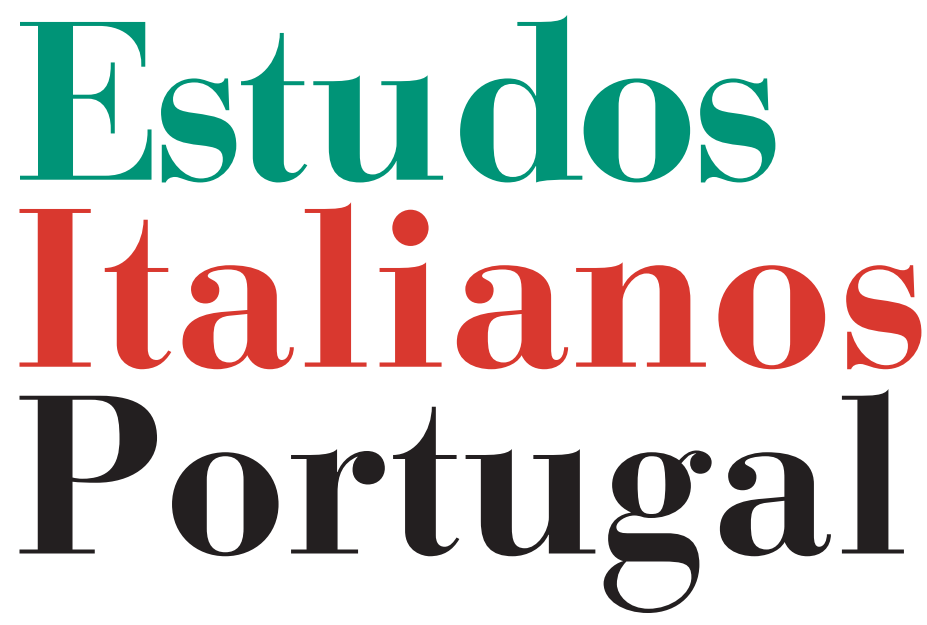

Instituto

Italiano

de Cultura

de Lisboa

Nova Série

$\mathbf{N}^{\mathbf{0}} 7$

2012 


\section{A VERTIGEM DO PRESENTE: CONSIDERAÇÕES SOBRE A POESIA ITALIANA DE FINAIS DO SÉCULO XX}

Maria BoCHICCHIO

La poesia in sé, non esiste - esiste soltanto, di volta in volta, e ogni volta inaudita, ogni volta imprevedibile e irrecusabile, ogni volta identica solo a se stessa, nelle parole dei poeti.

Giovanni Raboni

$\mathrm{Na}$ viragem para o século XXI, tornou-se insistente a denúncia de uma crise da literatura, e em particular da poesia, a despeito das expectativas próprias das grandes escansões epocais, que pedem antes anúncios de renovação. $\mathrm{O}$ século anterior tinha-se caracterizado por um incremento incessante das actividades teoréticas e práticas da poesia e da sua inter-relação. Já Barthes falava na chantagem que a teoria exerce sobre a prática em que a segunda se conformaria com a primeira para que esta diga bem dela. Mas a referência directa à experiência poética como fundamento da própria poesia é um dos factos mais relevantes de Novecentos. Trata-se de uma ideia de poesia que a época pós-moderna empurrou para dentro do novo milénio ainda este mal tinha começado, não sem procurar uma alternativa e garantir uma diferença quanto às orientaçóes estéticas no que respeita aos resultados poéticos, e salvaguardando uma certa continuidade e uma ligação com os desenvolvimentos dos poetas que vieram depois.

Além de tanto se ter proclamado a morte do romance, há muito que se fala[va] também do declínio da poesia em favor de uma era da prosa, que é uma espécie de prosaicização do real, postula-

\footnotetext{
* Filóloga, doutorada em literatura portuguesa pela FLUP e bolseira de pós-doutoramento da FCT. É docente de língua e linguística italiana na FLUC. Publicou além de numerosos artigos, O paradigma do pudor. Edição Crítico-genética de "A chaga" de José Régio (2002) e Carlos Queiroz, Fernando Pessoa. O poeta e os seus fantasmas (2011).
} 
dora de uma nova épica moderna nas suas precárias coordenadas de espaço e tempo relativos, a fazer com que nos interroguemos sobre as possibilidades da poesia enquanto fenómeno de consumo e/ou de moda, numa evidente desproporção quantitativa entre a proliferação dos escritores de poesia e aquilo que o mercado absorve, ou seja, uma mínima parte do produto poético. Paolo Volponi num dos seus diálogos, La mosca del capitale, afirma: "Non si racconta più [...] La narrazione, se vuole, è il bancone del supermercato... La poesia non so cosa sia, né come si compia" ${ }^{1}$. A isso junta-se uma crítica desorientada com as suas próprias ferramentas interpretativas (da linguística e do estruturalismo, passando pela semiótica e psicanálise, até aos novos estudos sobre a intertextualidade e a desconstrução), insuficientes para orientar e enriquecer o novo espaço poético, sempre mais alargado, híbri$\mathrm{do}^{2}$ e de vocação interdisciplinar, desta época multimédia e de alto risco de homogeneização e banalização da escrita. Por outro lado, princípios construtivos aparentemente inconciliáveis coexistem nas mesmas páginas. Há um crescente abandono das regras de oficina, a medida perde-se, a métrica dá lugar ao informal e o verso livre torna-se cada vez mais inorgânico. A arte literária tende a tornar-se amorfa, como que negando-se a si mesma e abandonando progressivamente quaisquer pretensões de individualidade estilística.

Depois das primeiras vanguardas do século XX, os autores têm em comum o sentimento de se moverem numa espécie de no man's land, num espaço que foi sendo deixado vazio, liberto das preocupações práticas e das fundamentações teóricas dos decénios anteriores, sem as suas vinculações e os seus preconceitos. Um espaço em que a liberdade e a gratuitidade tendem a confundir-se uma com a outra. Um vazio, porém, que ao mesmo tempo parece levar a uma nova focalização da dimensão literária, restau-

\footnotetext{
${ }^{1}$ Paolo Volponi, Le mosche del capitale, Torino, Enaudi, 1989, p. 122.

2 Para mais desenvolvimentos, cf. Lello Voce, "Appunti di dimamica dell'ibrido", Baldus, 1, 1991; e também Jameson Fredric, Il Postmoderno, o la logica culturale del tardo capitalismo, Milano, Garzanti, 1989, p. 10.
} 
rando as suas prioridades e redefinindo os seus fundamentos. Sintomática é a tentativa de conquistar e agregar novas formas do poético, ao mesmo tempo que perdem significado polaridades como tradição-vanguardas ou ordem-desordem. Notória é a preocupação da poesia que tende a reflectir, cada vez mais, sobre si própria, e a constituir como tema a sua linguagem e a sua gramática. $\mathrm{Na}$ ausência de uma língua verdadeiramente partilhada, o texto declara aquilo que o funda; sabe que não o possui e por isso enuncia-o como ideologia ou programa, intuindo-o afinal como protecção contra a insegurança sentida nesse terreno de múltiplas questôes.

Hoje como ontem, não faltam as polémicas frontais, contra ou a favor da tradição, as declarações poéticas colectivas, as antologias programáticas como I novissimi, poesie per gli anni sessanta ${ }^{3}$ de 1961, ou a antologia Poesia italiana della contraddizione $e^{4}$, de 1989, enfim, os manifestos e grupos poéticos que exprimem um regresso às vanguardas históricas, como o Gruppo $63^{5}$, e a explosão das neo-vanguardas da poesia dos anos 70 e 90.

Longe das preocupações metodológicas ou de uma gestão científica planeada da linguagem, os anos 70 regressam à oralidade, à vida pública da poesia, à sua teatralização por via da performance e da possível abertura dialógica e intersubjectiva. Acabou por triunfar o narcisismo, a reivindicação de um sublime elevado a partir da incursão poética. Em vez de um descentramento do eu, dava-se a sua restauração. Os textos começam a ser menos opacos, como se os poetas quisessem

\footnotetext{
${ }^{3}$ Alfredo Giuliani (org.), I novissimi, poesia italiana per gli anni 60, Milano, Rusconi e Paolazzi, 1961.

${ }^{4}$ F. Cavallo e M. Lunetta, (org.), Poesia italiana della contraddizione, Roma, Newton Compton, 1989.

${ }^{5}$ Movimento de neo-vanguarda, o Gruppo 63 constitui-se em Solunto (Palermo) em Outubro de 1963 e oficialmente durará até 1969. Faziam parte do grupo, entre outros, Luciano Anceschi, Nanni Balestrini, Edoardo Sanguineti, Umberto Eco. O objectivo era o de re-fundar uma linguagem poética fazendo tábua rasa das experiências literárias italianas, incluindo o neocrepuscularismo de Pasolini. O grupo sentia-se próximo da experiência francesa de "Tel quel" e da poesia americana underground.
} 
seduzir o leitor, mais do que traumatizá-lo através da "impertinenza dell'atto creativo [...] gioco futile e comico, lussuoso e eccessivo, irresponsabile e felice" ${ }^{\text {. }}$.

Terminada a produção poética dos anos 70, que do plano da concentração na produção dos textos deslizava para o da proposta da sua fruição, e em que os autores tinham entusiasticamente aberto as portas das próprias oficinas, enunciando as respectivas intenções, não se sabia para onde a poesia iria, mas achava-se que ela se movia fora dos espaços institucionalizados, abandonando a fria operatividade laboratorial e o cerebralismo pouco emotivo das vanguardas do anos 60 . Os anos 80 demonstrarão a desintegração do discurso poético proposto nos anos 70 e a sua marginalidade. A poesia redescobre uma dimensão mais privada e regressa em espaços institucionalizados, sempre mais fechados, de microeditoria especializada. Regressa também uma procura neo-expressionista, desregrada, aprofundada sobre as fragilidades do pós-moderno, o irracionalismo do desconstrucionismo e os efeitos da civilização multimédia. Os anos 80 tinham-se iniciado com a maciça retoma de uma actividade lírica fortemente centrada na subjectividade e com uma procura neo-expressionista relançada, seja nos encontros organizados por Alfabeta, seja na formação em 84, do Gruppo K.B. ${ }^{7}$. Este, juntamente com os poetas de velha geração da revista $B_{a l d u s}{ }^{8}$, convergirá em 1989, durante o festival MilanoPoesia (19 de Setembro), no Gruppo 93, última e apressada experiência colectiva do sécu-

\footnotetext{
${ }^{6}$ Giancarlo Pontiggia e Enzo di Mauro, "La statua vuota”, prefácio a La Parola Innamorata, I Poeti Nuovi 1976-1978, Milão, Feltrinelli, 1979. Ver também Giulio Ferroni, "A literatura de 68. Imaginação e batalha cultural", Imaginação e literatura, coord. Rita Marnoto, Coimbra, Instituto de Estudos Italianos da FLUC, 2009, pp. 11-31.

${ }^{7}$ As iniciais do Grupo derivam de um pequeno peixe transparente dos abismos o Kryptopterus Bicirrhis.

Faziam parte do K.B., entre outros, Lorenzo Durante, Gabriele Frasca, Marcello Frixione e Tommaso Ottonieri.

${ }^{8}$ Mariano Bàino, Biagio Cepollaro, Lello Voce.
} 
lo XX, o qual surge como paródia do Gruppo 63 e propóe temas novos de debate, como a contaminação ${ }^{9}$, a ausência de códigos, hierarquias, formas, o recurso a transtextualidades diacrónicas e sincrónicas, o citacionismo, com referência a Bakhtin, mas também à Semiosfera lotmaniana e a Gadda ${ }^{10}$, uma espécie de instalação interlinguística alegórica, atravessada por múltiplas citaçóes, num exercício de colagem explorando o puzzle e as suas peças, capaz de criar uma linguagem alternativa e dialéctica, feita de negação e oposição. O poeta da última geração, mais próximo do citacionismo alegórico, em linha com a tradição de Pagliarini e Voce, é Andrea Inglese ${ }^{11}$. No movimento de 93 também regressa o uso do dialecto, como pretensa novidade vanguardista... Os seus membros definem-se a si mesmos como posmodernisti critici $^{12}$. Algumas posiçóes, como as de nivelamento e platitude (appiattimento) do registo linguístico, ausência de hierarquizações ou uso experimental, por vezes problemático, dos materiais linguísticos em que se conglomeram diferentes tradições das escritas poéticas, nem sempre são partilhadas por todos os membros do grupo, como Gabriele Frasca e os poetas da área genovesa (Marco Berisso, Paolo Gentiluomo, Guido Cazerza, Piero Cademartori, entre outros). Estes poetas não aprovam o plurilinguismo nem a contaminação selvagem entre os géneros. Consideram a linguagem como um sistema, um princípio de ordem e organização, demasiado rico e sempre excedente à capacidade de compreensão

\footnotetext{
${ }^{9}$ A poesia deve ser impura, com matérias que provêm das várias áreas e sem distinção entre cultura alta e baixa.

${ }^{10}$ Carlo Emilo Gadda, Saggi, giornali, favole I, org. Liliana Orlando, Clelia Martignoni, Dante Isella, Milano, Garzanti, 1991, p. 436.

${ }^{11}$ Andrea Inglese, Prove dinconsistenza, intr. Giancarlo Majorino, em Poesia contemporânea. Sesto quaderno italiano, org. Franco Buffoni, Milano, Marcos y Marcos, 1998, pp. 115-159.

${ }^{12}$ Cecília Bello Minciacchi, "Ancora avanguardie?", Parola Plurale. 64 poeti italiani fra i due secoli, org. Giancarlo Alfano, Alessandro Baldacci, Andrea Cortellessa, Cecília Bello Minciacchi, Massimiliano Manganelli, Raffaella Scarpa, Fábio Zinelli, Paolo Zublena, Roma, Luca Sossella, 2005, pp. 613-626.
} 
do sujeito individual. Daí a proposta de Berisso, Frixione e Frasca, de regresso às formas métricas fechadas da tradição.

Marcello Frixione (1960), investigador de cibernética e de inteligências artificiais, educado na filosofia analítica, é considerado um dos mais interessantes poetas vanguardistas italianos das últimas décadas. A sua poesia faz constante referência à cultura científica e humanista. Desde a sua estreia com Diottrie $^{13}$ datada de 1991 e, dez anos mais tarde com Ologrammi (Rapallo, Zona, 2001), Marcello Frixione, marca o panorama poético italiano, seja pela sua passagem pelo Gruppo K.B. e pelo Gruppo 93, e sobretudo pela sua poesia compacta, pelo uso do léxico e das formas métricas que recupera da tradição lírica do maneirismo seiscentista, às quais agrega materiais da música rock e $р о p$, reconvertendo e alegorizando eventos, notícias que colhe da comunicação social, fragmentos de um imaginário colectivo banalizado ou degradado, para reflectir sobre o problema da percepção condicionado pelos média. In Diottrie, "ba ba ba baciami mia clori", o gaguejar em paródia de um célebre poema de Catulo (Carmina, V) e também em citação de uma música pop italiana produz uma reviravolta perceptiva vertiginosa, através do uso também paródico de materiais melódicos do nacional-populismo ou do kitch e de uma forma exagerada e provocatoriamente hiperliterária ao mesmo tempo que denuncia a impossível captura do presente:

\section{[...]}

Se presa in queste icone non rispondi

Se ad ogni simmetria del mio baciarti ahi sfuggi

Se resti e fuggi, - tu per mill'arti (offset!) oh vera figurata di dense carte (nice) mirata baciata ${ }^{14}$.

Também se compraz em "cosmogrammi tascabili (à la Raymond Queneau)”, onde cruza o saber científico e literá-

\footnotetext{
${ }^{13}$ Marcello Frixione, Diottrie, intr. Filippo Bettini, Lecce, Piero Manni, 1991.

${ }^{14}$ Marcello Frixione, "baci”, iii, p. 25.
} 
rio numa espécie de exercício de descrição histórico-natural conjugado com referências citacionais (T. S. Eliot, Ariosto, Montale...) e uma enumeração vertiginosa de partes do corpo humano:

S’innèstino piuttosto i nomi e il metro

all'humus alla linfa delle cose

dicon di viole lecci acanti rose

perché del paramecium no perché

càntano labri mani seni chiome

ma allora perchè non cromosomi

perché non la timina e l'uracile

anzicché aprile the cruellest month?

si canta dei ligustri e dei limoni

di donne cavalier d'armi e d'amori

di terre in strutturali complessioni

di nidi ciglia tombe solipsismo

e perché non di elettromagnetismo? ${ }^{15}$

Retomando a tradição sanguinetiana, os poetas do assim definido "nuovo stile genovese" insistem no carácter convencional e artificial da literatura. Em particular Marco Berisso (n. 1964) recupera de modo hiper-realístico a tradição regular dos séculos XII e XIII, convertendo-a numa estilística beckettiana em que o absurdo e o lúdico vão (a)de par num exercício de angústia, crueldade e abjecção:

Donna che piangi e ridi, il dito tendi

a forarmi nell'occhio

in questa notte estrema e senza trucchi;

piovimi in faccia il sonno, al vuoto rendi

questo stare in ginocchio

su mani e teste e lingue e piedi in mucchi

$(\ldots)^{16}$

${ }^{15}$ Marco Frixione, "cosmogrammi tascabili (da Raymond Queneau)", iii, p. 81.

${ }^{16}$ Berisso, "Donna che piangi e ridi il dito tendi", Annali, Salerno, Oèdipus, 2002. 
A recuperação das formas métricas antigas representa, não uma nostalgia do passado, mas sim uma insubordinação quanto ao problemático princípio do verso livre ${ }^{17}$, por via de uma utilização transgressiva dos cânones poéticos de outrora.

Outro poeta dos últimos anos que brilha pela sua originalidade é Alessandro Fo (n.1955), poeta, latinista e filólogo. Dos seus versos transparece o trato com uma latinidade tardia. A sua poesia é de um virtuosismo elaborado com subtis ascendências virgilianas ${ }^{18}$. Considerado por Franco Buffoni como "il poligrafo totale"19, os seus versos, alexandrinos versáteis, pacatos e cheios de rebuscamento preciosista ${ }^{20}$, são escritos ao sabor de um crepuscularismo autoindulgente e paródico, na leveza e ironia com que se servem da quotidianidade banal. Em "l'offerta" de Bucoliche al telescopio escreve:

Come accorsi alla pena di un poeta attratti da una musica che li domini, e più dalla bontà, a fargli compagnia vorrei disporre in un corteo gli animali, a confluire con il nostro volto: i topi dal fienile, i maiali rosa le oche e cigni che riflettono elefanti martore, emù, e i più eccezionali veduti un giorno in un negozio di giocattoli, l'orfea, la dàfnia, l'urogallo, l'uro

l'urìa, il gallione, gli urodèli, il terzuolo quelli d'acqua nel fiume

${ }^{17}$ Niva Lorenzini, La nuova poesia italiana del 900, Bologna, il Mulino, 1999, pp. $126,127$.

${ }^{18}$ Silvia Longhi, Autografo, 34, gennaio-giugno 1997, pp. 137-142.

${ }^{19}$ Franco Buffoni, Introduzione ad Alessandro Fo, A ricordo del grande Bologna, em Poesia contemporanea. Secondo quaderno italiano, Milano, Guerini e associati, 1992, p. 114.

${ }^{20}$ Gianfranco Agosti, Semicerchio, 15, 1996/2, p. 72. 
e (ancora non so come) quelli in volo.

Quasi che, uscito dalla macchia vegetale, il prodigioso progresso della loro vita fatta di moto e trasporto interiore significasse liberamente anche l'ingresso nella presenza al dolore e al vuoto. Presso la mangiatoia una statuina con i capelli rossi (l'amore di quel poeta) ne porge uno travolto:

Errore. L'origine riferimento non è stata trovata. Come l'hai creato così riprendilo.

Sicuramente è morto più puro di noi uomini”.

E su, l'Orsa Maggiore ${ }^{21}$.

Os poetas dos anos 90 pertencem a uma geração que nasceu e cresceu em plena comunicação televisiva, plenamente imersa na comunicação multimediatizada. Mas têm predecessores. Convém recordar Patricia Valduga que, já em 1982, na sua recolha Medicamenta ${ }^{22}$, põe a sua ágil oficina formal ao serviço da expressão sem rodeios do desejo sexual. Inspirando-se na poesia erótica dos clássicos gregos e latinos e também no Cânticos dos Cânticos, esta autora concilia a precisão técnica com a força da vibração existencial do Eros, num jogo irónico entre o verbo e as pulsões da carne levado a uma extrema dialectização verbal (verso... inverso ... controverso):

Sa sedurre la carne la parola, prepara il gesto, produce destini...

E martirio è il verso,

è emergenza di sangue che cola

e s'aggruma ai confini

del suo inverso sessuato, controverso.

\footnotetext{
${ }^{21}$ Alessandro Fo, "Lofferta", Bucoliche al telescopio, Lucca, Una cosa rara, 1996.

22 Patricia Valduga, Medicamenta, Parma, Guanda, 1982.
} 
De resto, a necessidade de recorrer a formas clássicas e de as recuperar como ferramentas cognoscitivas, tem precedentes na obra de um autor injustamente esquecido pela crítica contemporânea, Edoardo Cacciatore, já activo desde os anos '50, na sua recolha La puntura dell'assillo ${ }^{23}$, de 1986:

Zonzeggia il linguaggio eppure obbedisce

Al fulmine spiccio che coglie nel segno

[...]

Linguaggio è tale erche da una frotta

Intende ottenere una docile fresa

O paradoxo aparente dos autores que integram o Gruppo 93 está na coexistência de uma proposta vanguardista com a revalorização quase provocatória das formas clássicas e dos vernáculos pós-modernos, tudo ironicamente contraposto, nessa recuperação de um sentido da estabilidade que se desenvolve no coração da própria instabilidade, própria das modas sincopadas da linguagem audiovisual e das suas acelerações competitivas no espaço público. Daí uma necessidade de compreensão, embora pareça que se assiste menos do que anteriormente a confrontos de escolas arvoradas em detentoras da verdade literária. Assistimos a uma praxis dos poetas que muitas vezes é descentrada no tocante ao que se proclama e encontramos autores que, na teorização, partilham uma mesma visão da poesia, mas no acto da escrita são muito diferentes entre si. Vivemos poeticamente sem pontos de referências, num tempo de deriva. Numa perspectiva semelhante, Tommaso Ottonieri, pseudónimo de Pomilio, activo desde os anos 80 , como crítico e poeta, defende em La plastica della lingua. Stili in fuga lungo una età postrema ${ }^{24}$,

${ }^{23}$ Edoardo Cacciatore, "La fulmineità del linguaggio", La puntura dell'assillo, Milano, Società di poesia, 1986.

${ }^{24}$ Tommaso Ottonieri, La plastica della lingua. Stili in fuga lungo una età postrema, Torino, Bollati Borighieri, 2000. 
a ideia de que a poesia actual é plástica, ou seja refere-se à capacidade de automodificação e adaptação comportamental da língua poética:

Non so se sia più vero che è 'plastico' lo stile della Plastica della língua, cioè flessibile, mimetico, metamorfico, adattabile alle lingue che osserva o di cui si riveste; o se, piuttosto, tutte queste lingue non siano riplasticate in un fluido critico, insomma - quella metafiction dove ogni simulazione di realtà - testuali e non - diviene plástica di uno stile (stile in movimento) e non c'è che il movimento che possa tenerci uniti. D'altra parte, come sapeva Thomas Pynchon - e, prima di lui, il suo fraterno amigo Richard Farinã , - è Plasticman l'unico supereroe che possa opporsi all'Uomo Modulare. ${ }^{25}$

É evidente que hoje existe uma descontinuidade moderna-pós-moderna $a^{26}$ da poesia. A sua acentuada marginalidade, o seu necessário ecletismo horizontal, a confusão entre cultura "cultivada" e cultura popular, testemunham um esvaziamento de conteúdo da poesia contemporânea ou seja o poeta fala a partir de uma condição privada de legitimação forte, propensa a extravasar em direcção a um não-sentido, a uma perda de coordenadas, uma interrupção da tradição da modernidade e sobretudo a uma perda de ligação entre os autores, obras e movimentos, dificultando cada vez mais a tarefa do leitor. A chamada "promessa de arbítrio" ("qualquer coisa está igualmente bem") do pós-moderno corre o risco de ser uma armadilha que parece condenar-nos ao confronto,

${ }^{25}$ Id., "Scritture in movimento", Poetiche contemporanee, org. Tommaso Lisa, Pieve al Pioppo, Zona, 2006, pp. 107-108.

${ }^{26}$ Entende-se por pós-moderno na Itália a crise de valores do sistema sociocultural moderno e da sua subversão de hierarquias ontológicas. Em discussão o conceito de superação do moderno a que o prefixo alude e o de continuidade ou de intensificação do moderno ou seja uma fase de hipermodernidade. Para um maior aprofundamento, ver: Federico Pellizzi, Bollettino '900. Electronic newsletter on '900 Italian Literature, I, 1, Agosto 1995, e Peter Burger, Teoria dell'avanguardia, Torino, Bollati, 1990, pp. 123-128. 
limitado e frustrante, com microscópicos nichos de experiência auto-satisfeitos consigo mesmos, indiferentes, se não mesmo à totalidade, pelo menos à esperança de que qualquer coisa de não alienante seja possível ou praticável. A poesia tardia novecentista é pouco selectiva e talvez seja este o ponto decisivo. Todos nós, poetas e críticos, usamos a única palavra poesia para dizer demasiadas coisas diferentes. E quanto à extensão da audiência de críticos e poetas, ocorre remeter para o Alexandre O’Neill de "O lanterna vermelha": "Quem nos lê a nós? São vocês (e nós...) / Quem vos lê a vocês, somos nós (e vocês...)"27. Uma poesia mais orientada para uma estética da recepção, a viver também, para além das crises e fragmentações do eu, uma crise do "tu poético", da "credibilidade" do destinatário, daquele que já desde Baudelaire, é o "hyppocrite lecteur, mon semblable, mon frère". $\mathrm{Ou}$, como diria Saba, simulando postular a inutilidade da comunicação poética e supondo que o leitor se envergonharia de aceitar uma suspensão da descrença (suspension of disbelief),

Questo libro che a te dava conforto, buon lettore, è vergogna a chi lo crebbe.

Parlava come un vivo ed era (avrebbe dovuto, per decenza, essere) morto. ${ }^{28}$

Feitas estas consideraçōes, as reflexōes, mesmo avulsas ou fragmentárias, que deixo neste artigo, pretendem tentar uma abordagem, conquanto pontual, provisória ou não sistemática, de alguns momentos da poesia italiana das últimas décadas que considero relevantes. É provável que a própria tradição italiana possua, mais do que outras, e até talvez como traço mais específico, um carácter de multiplicidade que não tolera qualquer tipo de simplificação e ainda menos

${ }^{27}$ Alexandre O’Neill, “Lanterna Vermelha”, Poemas com endereço. Poesia completa, Lisboa, Assírio \& Alvim, 2000, p. 207.

${ }^{28}$ Umberto Saba, Tutte le poesie, a cura di A. Stara, Milano, Mondadori, 1988, p. 627. 
de reductio ad unum; uma variedade que, nos melhores casos, significou por si mesma riqueza e pluralismo, mas que tantas vezes caiu na fragmentação, no emaranhamento e no vício de uma recíproca negação das partes ou das vozes. É o que faz, por exemplo, a grandeza e a dificuldade de um Edoardo Sanguineti, ao mesmo tempo especialista de Dante e da história da literatura, capaz de parodiar François Villon, inimitável apostador em descontinuidades linguísticas e nas ironias de múltiplos jogos semânticos, nas suas provocações e estridências de vanguarda.

Finalmente, o trajecto que acaba de ser feito pela poesia italiana das últimas décadas não pode deixar de pôr em destaque duas figuras de primeiro plano, Alda Merini e Valerio Magrelli.

Como já tive oportunidade de observar, Alda Merini constitui um verdadeiro caso literário dos últimos anos. Isso deve-se, em parte, à sua particular história biográfica e ao interesse que a autora suscitou no mundo cultural e jornalístico.

La Terra Santa (1984) - considerada a sua obra-prima assinala o início de uma poética impregnada pela devastadora experiência do manicómio: líricas de uma intensidade poderosa, onde a realidade é sublimada e deformada pelo delírio e pela loucura. A partir de Dopo tutto anche tu (2004), Merini tranforma-se numa poetisa de ocasião, ou de improviso, com o furor que lembra as grandes improvisadoras "virtuoses" dos séculos XVIII e XIX (muitas vezes os poemas não são escritos, mas ditados ao telefone a quem organizava os seus volumes).

A obra poética de Alda Merini é extensa. Mas um elemento de continuidade ao longo da sua produção é a frequente sobreposição de imagens terrenas (maioritariamente eróticas) e religiosas (mais especificamente bíblicas). Uma espécie de sincretismo blasfemo influenciado pelo modelo da Commedia de Dante, no qual tende a aplicar a sua vivência a um tipo de leitura figurativa. A autora constrói uma lenda biográfica a partir de elementos da sua própria existência, que é assim 
apresentada em função da posterior criação poética. A poesia de Alda Merini é sempre uma "confissão" fantástica e teatral de uma experiência em clave profética, mas com curto-circuitos inquietantes.

Também já escrevi que Alda Merini é uma poetisa com uma escandalosa evidência órfica. Um preço que a própria preferiria não ter pago: teria de boa vontade passado sem o manicómio e a dor sem limites que conheceu - e que a sua poesia dá a conhecer - se o preço a pagar tivesse sido o de não escrever mais. E é esse o ponto: a literatura não vale a vida. E isso transpira de cada linha, de cada verso de uma criação poética em que se esbatem desesperadamente as fronteiras entre a experiência vivida e a escrita literária.

$\mathrm{Na}$ poesia de Valerio Magrelli (n. 1957), entrecruzam-se erudição e ironia, reflexão antropológica e consciência dos progressos técnicos, vida quotidiana e herança simbolista. E, aqui e ali, discretos reflexos de Dante, como que situam um ponto de partida essencial: a língua italiana, não obstante a equação prática da irrupção do silêncio para a palavra e as suas margens. A escrita como "morte serena” dá bem a medida existencial dessa reflexão.
Preferisco venire dal silenzio
per parlare. Preparare la parola
con cura, perché arrivi alla sua sponda
scivolando sommessa come una barca,
mentre la scia del pensiero
ne disegna la curva.
La scrittura è una morte serena:
il mondo diventato luminoso si allarga
e brucia per sempre un suo angolo ${ }^{29}$.

${ }^{29}$ Valerio Magrelli, "Preferisco venire dal silenzio", Poesie (1980-1992), Torino, Einaudi, 1996, p. 10. 
A arte poética de Magrelli é, na verdade, uma metalinguagem que se fixa obsessivamente no mesmo tema, que se encaixa e desencaixa sobre a página, não como reflectido num espelho, mas na translucidez de um vidro com uma certa impessoalidade autoral, no jogo entre quem faz o texto e aquilo que se revela nele.
$[\ldots]$
e anche i temi poi sono diversi
anzi c'è un solo tema
e ha per tema il tema, come adesso.
Questo per dire quanto
resta di qua della pagina
e bussa e non può entrare,
e non deve. La scrittura
non è specchio, piuttosto
il vetro zigrinato delle docce,
dove il corpo si sgretola
e solo la sua ombra traspare
incerta ma reale.
E non si riconosce chi si lava
ma soltanto il suo gesto.
Perciò che importa
vedere dietro la filigrana,
se io sono il falsario
e solo la filigrana è il mio lavoro ${ }^{30}$.

Dante serve de pretexto para falar do código genético da poesia, a partir de uma citação do Canto XVII do Inferno. É um DNA helicoidal e elástico, interpelado pelo poeta, entrançando rimas que se misturam nos séculos em direcção ao futuro da língua mãe.

\footnotetext{
${ }^{30} \mathrm{Ib}$., p. 15.
} 
A te Dna della poesia

Ella sen va notando lenta lenta:

rota e discende ma non me n'accorgo

se non che al viso e di sotto mi venta

A te Dna della poesia

elica e elastico

avviticchiati a forza

a malincuore treccia

attorcigliata torte e ritorte

rime

di un aereo giocattolo

che appena liberate

frullano via nei secoli

verso il futuro della lingua madre ${ }^{31}$.

A ironia da busca do significado, por sua vez, dá estes trabalhos extremamente fatigantes num mundo em que tudo pode ter-se imobilizado:

Giochi:

Rebus

E' un mondo senza tempo

e senza vento.

Tutto sta fermo

e faticosamente significa.

Enorme è la fatica del significare

in questo cantiere del senso.

Ogni parola è una massicciata

di lettere e figure.

Tutto pesa ${ }^{32}$.

${ }^{31} \mathrm{Ib} ., \mathrm{p} .287$.

${ }^{32}$ Id., Didascalie per la lettura di un giornale, Torino, Enaudi, 1999. 
Enfim, Valerio Magrelli tem plena consciência daquilo a que poderíamos chamar "poesia, modo de (usar) emprego", entre recarga e armadilha, acumulação de sentido e rumores dentro de uma fraude mítica e suprema, a da penetração no espaço absoluto do poema primordial, por via de um humano artifício:

\section{La poesia}

Le poesie vanno sempre rilette, lette, rilette, lette, messe in carica; ogni lettura compie la ricarica, sono apparecchi per caricare senso; e il senso vi si accumula, ronzio di particelle in attesa, sospiri trattenuti, ticchettii, da dentro il cavallo di Troia ${ }^{33}$.

O século XXI abre com a lição destes autores. A maior parte deles continua a escrever e a traçar pistas inovadoras para a poesia italiana do século XXI, a que dão um timbre inimitável no contexto da demais poesia europeia do seu tempo. 